\title{
Outcome Prediction in Acutely Intoxicated Patients Admitted to Intensive Care Unit
}

\author{
Assmaa A. Assaf, Manal A. Abd El Kareem ${ }^{1}$ and Marwa A. Hasb Elnabi ${ }^{2}$ \\ ${ }^{1}$ Forensic Medicine \& Clinical Toxicology department, Faculty of Medicine, Ain Shams University. \\ 2 Forensic Medicine \& Clinical Toxicology department, Faculty of Medicine, Sohag University.
}

Egypt.

\begin{abstract}
:
Background: Acute poisoning represents a significant proportion of intensive care unit admissions. Even though the overall mortality may be low, they may consume considerable intensive care unit (ICU) resources. Early diagnosis and rapid initiation of appropriate therapy in emergency department and ICU are critical for decreasing hospital morbidity and mortality in poisoned patients. The objective of this study is to determine predictors of outcome of acutely intoxicated patients in intensive care unit which may improve the course of management and decide the pathway of care.

Methodology: This is an observational cross sectional retrospective study of 321 acutely intoxicated patients admitted to intensive care unit of Poison Control Center (PCC) in hospitals of Ain Shams University. Information was collected from the sheets and computerized data base of the patients after obtaining the permission of the director of PCC and the regional ethics committee. The results were revised, coded and organized for statistical analysis.

Results: The total number of acutely intoxicated patients admitted to ICU of PCC in hospitals of Ain Shams University in the selected period of study was 321 patients. There were 265 patients (82.6\%) survived with no complications, 30 patients (9.4\%) survived but developed complications and 26 patients (8\%) died. The study showed statistically significant difference between uncomplicated, complicated and dead cases as regards mode of toxicity, causative Agent, heart rate, systolic blood pressure, respiratory rate, skin discoloration, Glasgow coma scale (GCS), blood pH, emesis or lavage, activated charcoal, dialysis, endotracheal intubation, mechanical ventilation and dopamine therapy.

Conclusion: It could be detected by statistical analysis that causative agent, heart rate, systolic blood pressure, respiratory rate, blood $\mathrm{pH}$, mechanical ventilation and dopamine therapy were significant outcome predictors of acutely poisoned patients in intensive care unit. From the previous results, our study recommends that these predictors of outcome should be assessed routinely and as early as possible to evaluate the severity, improve the course of management and deciding the pathway of care.
\end{abstract}

Key words

Predictors of outcome, ICU, GCS, complications.

\section{Introduction}

$\mathrm{A}$ cute poisoning represents a significant proportion of intensive care unit admissions and even though the overall mortality may be low, they may consume considerable intensive care unit resources (Singh et al., 2011).

Toxicologic conditions are encountered in patients with acute poisoning in intensive care unit due to intentional or unintentional exposure to therapeutic or illicit drugs. Additionally, toxicities related to medical interventions may occur in hospitalized patients (Philip and Janice, 2008).
Intensive care unit management of poisoned patient requires rapid diagnosis and supportive care while in some cases providing specific antidotal treatment (Donna et al., 2011).

Accurate prognostic information for critically ill patients could help clinicians with decisions like whether and when patients might benefit from intensive care. From the perspectives of families, prognostic information is welcome in discussions about the benefits of intensive care and completeness of this information is 
an independent determinant of family satisfaction (Heffner and Barbieri, 2000; Heyland et al., 2002).

\section{Aim of the work}

The aim of this work is to determine the predictors of outcome of acutely intoxicated patients in intensive care unit of the Poison Control Center in hospitals of Ain Shams University.

\section{Methodology}

This is an observational cross sectional retrospective study of 321 acutely intoxicated patients in ICU of PCC in hospitals of Ain Shams University in the period from 1/7/2011 to 31/1/2012. An approval from the Ethical Committee and the permission of the director of PCC were taken. Information was collected from the sheets and computerized data base of the patients with the confidentiality of these records. The basis of acute poisoning diagnosis was positive history, clinical pictures and initial laboratory tests specific to certain poisons.

The following data was collected from the sheet of each patient:

(A) Demographic Data.

(B) Toxicological data.

(C) Physical findings on admission.

(D) Reported investigational data and treatment received

(E) Outcome of the patients:

The patients were classified according to the outcome into 3 groups' uncomplicated, complicated and dead.

\section{Statistical Analysis}

The obtained results were revised, coded and organized for statistical analysis by SPSS. Mean and standard deviation was done for numerical data. Frequency and percentage were obtained for non-numerical data.

Comparison between outcome groups was tested using KruskalWallis Test. Linear regression analysis was used to identify significant predictors of outcomes. P-value was considered statistically significant if $<0.05$.

\section{Results}

The total number of acutely intoxicated patients admitted to ICU of PCC in hospitals of Ain Shams University in the selected period of study was 321 patients. In the current study, $36.7 \%$ of patients were 15 to $<25$ years and $6.9 \%$ of them were 5 to $<15$ years old, $52.6 \%$ of patients were females and $47.4 \%$ were males (table, 1 ). Most of poisoning cases were due to pharmaceutical agents (36.5\%), followed by organophosphorus compounds (15.3\%), tramadol (14.3\%), snake bites (5.7\%), carbon monoxide (4.9\%) and corrosives (4\%), other toxic agents (19.3\%) (kerosene, scorpion, alcohol, hydrogen sulphide, ciguatera, PPD Paraphenylenediamine \}) (table, 2). As shown in table (3) $52 \%$ of cases were suicidal, route of exposure in $84.7 \%$ of patients was oral and the mean delay time of patients was 6.09 hours while $54.9 \%$ of cases showed delay time 2 - 6 hours.

The outcome of the patients as shown in table (4) was as the following: 265 patients were survivors with no complications representing about (82.6\%), 30 patients were survivors with complications representing about (9.4\%) and 26 patients died representing about (8\%). The most frequently encountered complications were dysphagia, bleeding and anemia in (26.6\%), followed by intermediate syndrome in (23.3\%), cognitive dysfunction in (16.6\%), rhabdomyolysis in (10\%), renal failure in (6.6\%), then, hepatotoxicity in (3.3\%), disseminated intravascular coagulation in (3.3\%), myopathy in (3.3\%), pneumonia in (3.3\%) and pneumothorax in (3.3\%) (table, 5). The study showed statistically significant difference between uncomplicated, complicated and dead cases as regards mode of toxicity, causative Agent, heart rate, systolic blood pressure, respiratory rate, skin discoloration, Glasgow coma scale (GCS), blood pH, emesis or lavage, activated charcoal, dialysis, endotracheal intubation, mechanical ventilation and dopamine therapy (table, 6). No statistically significant differences in age, sex, route of exposure, delay time, body temperature, random blood glucose, serum potassium levels, multiple doses activated charcoal, alkalinzation of urine and antidotes administration among uncomplicated, complicated and dead cases. Table (7) showed that predictors of outcome were heart rate, systolic blood pressure, respiratory rate, causative agent, blood $\mathrm{pH}$, mechanical ventilation and dopamine therapy.

Table (1) statistical analysis: Number and percentage of the studied patients as regard sociodemographic data.

\begin{tabular}{|l|c|c|c|}
\hline \multicolumn{2}{|c|}{} & Number & Percentage \% \\
\hline Age group (years) & $<\mathbf{5}$ & 68 & $21.2 \%$ \\
\cline { 2 - 4 } & $\mathbf{5 -}$ & 22 & $6.9 \%$ \\
\cline { 2 - 4 } & $\mathbf{1 5 -}$ & 118 & $36.7 \%$ \\
\cline { 2 - 4 } & $\mathbf{2 5 -}$ & 58 & $18 \%$ \\
\cline { 2 - 4 } & $\mathbf{3 5 -}$ & 24 & $7.5 \%$ \\
\cline { 2 - 4 } & $\geq \mathbf{4 5}$ & 31 & $9.7 \%$ \\
\hline Sex & Male & 152 & $47.4 \%$ \\
\cline { 2 - 4 } & Female & 169 & $52.6 \%$ \\
\hline
\end{tabular}


Table (2) statistical analysis: Number and percentage of the studied patients as regard causative agents of poisoning.

\begin{tabular}{|l|c|c|}
\hline \multicolumn{1}{|c|}{ The causative agents } & Number & Percentage $\%$ \\
\hline Pharmaceutical agents & 117 & $36.5 \%$ \\
\hline Organophosphates & 49 & $15.3 \%$ \\
\hline Tramadol & 46 & $14.3 \%$ \\
\hline Snake bite & 18 & $5.7 \%$ \\
\hline Carbon monoxide & 16 & $4.9 \%$ \\
\hline Corrosives & 13 & $4 \%$ \\
\hline Other toxic agents & 62 & $19.3 \%$ \\
\hline Total & 321 & $100 \%$ \\
\hline
\end{tabular}

Table (3) statistical analysis: Number and percentage of mode of toxicity, route of exposure and delay time in the studied patients.

\begin{tabular}{|c|c|c|c|}
\hline & Number & Percentage \% \\
\hline \multirow[t]{3}{*}{ Mode of toxicity } & Accidental & 116 & $36.2 \%$ \\
\hline & Suicidal & 167 & $52 \%$ \\
\hline & Therapeutic error & 38 & $11.8 \%$ \\
\hline \multirow[t]{5}{*}{ Route of exposure } & Oral & 272 & $84.7 \%$ \\
\hline & Inhalation & 20 & $6.3 \%$ \\
\hline & IM or SC & 4 & $1.3 \%$ \\
\hline & Bite or Sting & 22 & $6.8 \%$ \\
\hline & Dermal & 3 & $0.9 \%$ \\
\hline \multirow[t]{5}{*}{ Delay time } & $<2$ & 58 & $18 \%$ \\
\hline & $2-6$ & 176 & $54.9 \%$ \\
\hline & $>6$ & 87 & $27.1 \%$ \\
\hline & Mean \pm SD & \multicolumn{2}{|c|}{$6.09 \pm 1.5$} \\
\hline & Range & \multicolumn{2}{|c|}{$1-120$} \\
\hline
\end{tabular}

IM: Intramuscular-SC: Subcutaneous

Table (4) statistical analysis: Number and percentage of the outcome of the studied patients.

\begin{tabular}{|l|c|c|}
\hline \multicolumn{1}{|c|}{ Outcome } & Frequency & Percentage \\
\hline Survived (with no complications) & 265 & $82.6 \%$ \\
\hline Survived (with complications) & 30 & $9.4 \%$ \\
\hline Died & 26 & $8 \%$ \\
\hline Total & 321 & $100 \%$ \\
\hline
\end{tabular}

Table (5) statistical analysis: Number and percentage of the studied patients as regard complications

\begin{tabular}{|l|c|c|}
\hline \multicolumn{1}{|c|}{ Complications } & Number & percentage \\
\hline Dysphagia, bleeding and anemia & 8 & $26.6 \%$ \\
\hline Intermediate syndrome & 7 & $23.3 \%$ \\
\hline Cognitive dysfunction & 5 & $16.6 \%$ \\
\hline Rhabdomyolysis & 3 & $10 \%$ \\
\hline Renal failure & 2 & $6.6 \%$ \\
\hline Hepatotoxicity & 1 & $3.3 \%$ \\
\hline Myopathy & 1 & $3.3 \%$ \\
\hline DIC & 1 & $3.3 \%$ \\
\hline Pneumonia & 1 & $3.3 \%$ \\
\hline Pneumothorax & 1 & $3.3 \%$ \\
\hline Total & 30 & $100 \%$ \\
\hline
\end{tabular}

DIC: Disseminated intravascular coagulation 
Table (6) statistical analysis: Kruskal Wallis test of mode of toxicity, causative Agent, heart rate, systolic blood pressure, respiratory rate, skin changes, GCS, blood $\mathrm{pH}$, emesis or lavage, activated charcoal, dialysis, endotracheal intubation, mechanical ventilation and dopamine therapy in relation to outcome of the studied patients.

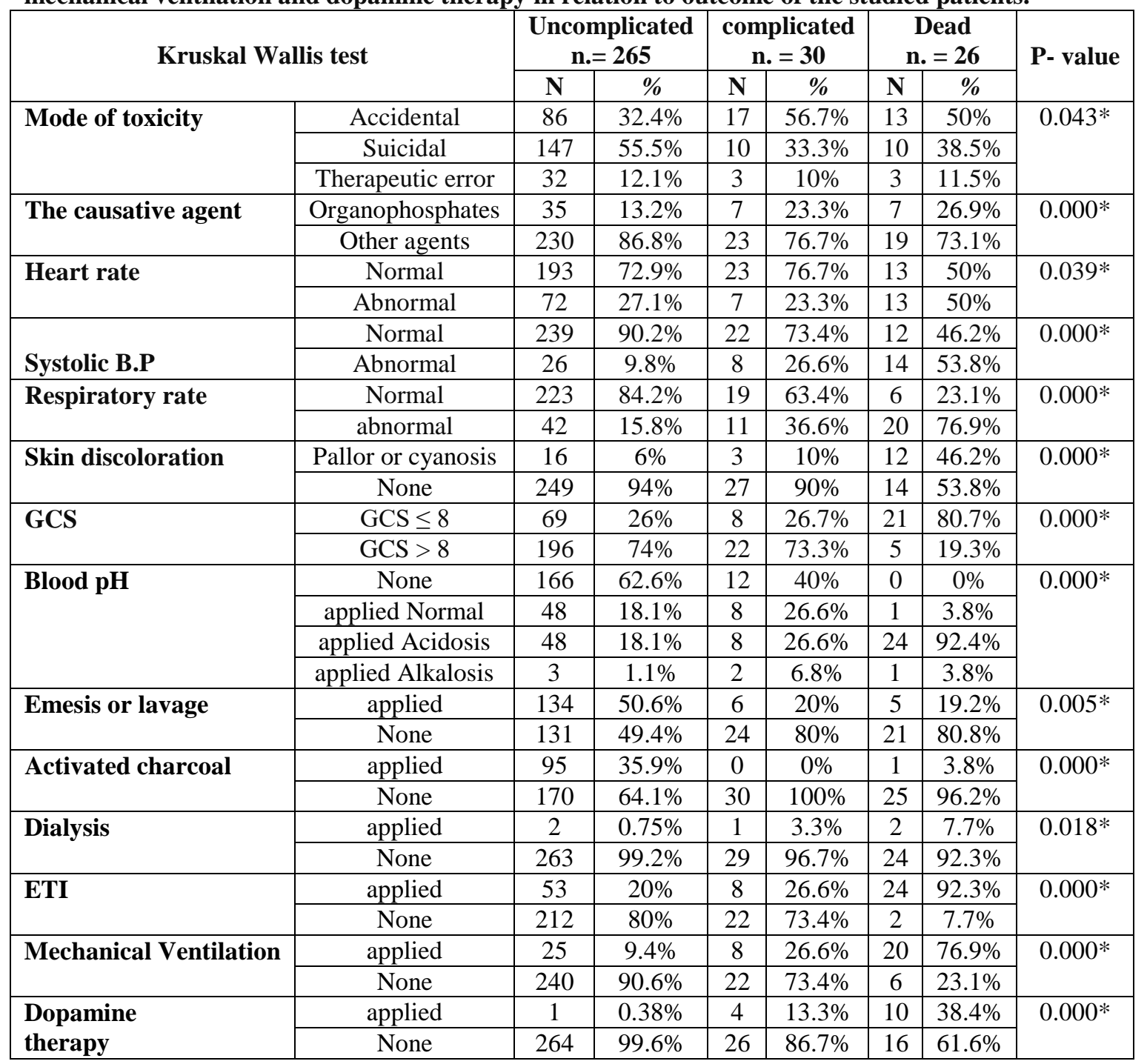

$* P$ is considered statistically significant if $\leq 0.05$, GCS: Glasgow Coma Scale, ETI: Endotracheal intubation

Table (7) statistical analysis: Linear regression analysis of statistically significant parameters in relation to outcome.

\begin{tabular}{|l|c|c|c|c|}
\hline \multirow{2}{*}{ Linear regression analysis } & \multicolumn{2}{|c|}{ Unstandardized C. } & Standardized C. & \multirow{2}{*}{ P- value } \\
\cline { 2 - 5 } & B & Standard Error & Beta & \\
\hline Mode of toxicity & -.033 & .037 & -.038 & 0.376 \\
\hline Causative Agent & -.027 & .005 & -.264 & $0.000^{*}$ \\
\hline Heart rate & .116 & .056 & .089 & $0.039^{*}$ \\
\hline Systolic blood pressure & -.208 & .074 & -.125 & $0.005^{*}$ \\
\hline Respiratory rate & -.146 & .063 & -.103 & $0.022^{*}$ \\
\hline Skin discoloration & .075 & .093 & .037 & 0.419 \\
\hline Conscious level & .004 & .011 & .027 & 0.739 \\
\hline Blood pH & .085 & .038 & .129 & $0.024^{*}$ \\
\hline Emesis or lavage & -.053 & .030 & -.072 & 0.078 \\
\hline Activated charcoal & .050 & .060 & .038 & 0.405 \\
\hline Dialysis & .220 & .195 & .046 & 0.260 \\
\hline Endotracheal intubation & -.004 & .085 & -.003 & 0.963 \\
\hline Mechanical ventilation & .314 & .097 & .196 & $0.001^{*}$ \\
\hline Dopamine therapy & .874 & .123 & .311 & $0.000^{*}$ \\
\hline
\end{tabular}

C: Coefficients, ${ }^{*} P$ is considered statistically significant if $<0.05$. 


\section{Discussion}

Acute poisoning is a frequent etiology of admission to emergency departments (ED) and always requires treatment in the intensive care unit (ICU). Early diagnosis and rapid initiation of appropriate therapy in ED and ICU are critical for decreasing hospital morbidity and mortality in patients with acute poisoning (Islambulchilar et al., 2009).

In this study 265 patients (82.6\%) improved and were discharged without complications, 30 patients (9.4\%) survived but with complications and 26 patients (8\%) died during treatment in the ICU. These results differ from those reported by Hassanian et al., (2007) where ICU mortality in poisoned patients was $18.6 \%$. On the other hand, two studies done in Germany and Hong Kong reported that mortality of poisoning in ICU were respectively 0.7 and 3\% (Schwake et al., 2009). Lam et al., (2010) attributed these different results to the extreme variation in reported mortality and criteria of ICU admission across hospitals and countries.

In our study, the most frequently encountered complications were dysphagia, bleeding and anemia followed by intermediate syndrome and cognitive dysfunction. The most frequent agents involved were corrosives, organophosphorus compounds and carbon monoxide. Taghaddosinejad et al., (2012) reported that the most common complications of sever poisoning cases in ICU were coma, rhabdomyolysis and aspiration pneumonia where the most frequent agents involved were benzodiazepines and tricyclic antidepressant.

The present study showed that there was statistically significant difference between the 3 groups in the mode of toxicity where nearly half of complicated cases and dead cases were accidental. These findings are similar to those of Lee et al., (2008) who stated that there was statistically significant difference between survivors and non-survivors as regard mode of toxicity. Agran et al., (2001) and Khadka and Ale, (2005) explained the high incidence of complicated and dead cases in accidentally intoxicated patients as accidental poisoning is common in children under five years. In the current study, statistically significant difference was among uncomplicated, complicated and dead cases as regard causative agents. Organophosphorus compounds and carbon monoxide carried the highest mortality risk (26.9\%) followed by corrosives. This is in accordance with Goel and Aggarwal, (2007) and Malangu and Ogunbanjo, (2009) who reported that more than half of dead cases in their study due to poisoning with Organophosphorus compounds and carbon monoxide. Davies et al., (2008) mentioned that organophosphorus poisoning had high mortality, most patients died from cardiorespiratory failure and many patients had cardiorespiratory arrests after admission. Significant exposures of Carbon monoxide cause hypotension, dysrhythmia, ischemia, infarction, and, in extreme cases, cardiac arrest (Kao and Nanagas, 2004). The reverse was reported by Lund et al., (2012) where more than half of the mortality cases caused by substances of abuse and Litovitz et al., (2001) mentioned that drugs like analgesics, sedatives and antidepressants were associated with high mortality rate. Disparities between the results of these studies are most likely due to the difference in access, as well as the ages of affected victims (Saddique, 2001).

As regards heart rate, systolic blood pressure, respiratory rate and skin discoloration there was statistically significant difference between the 3 groups in the present study. These results go with those of Yu et al., (2012) who mentioned that there were significant differences between survivors and non-survivors as regard heart rate, systolic blood pressure, and respiratory rate. He denoted that the patients with extremely abnormal vital signs had the greatest risk of in-hospital mortality. Also, Baumann and Strout, (2007) found that the Emergency Severity Index triage score, which incorporates vital signs into its algorithm, accurately assesses the risk of patients for hospitalization and mortality. The decrease in blood pressure can then cause blood vessels to contract resulting in a pale or bluish skin color and seizures in advanced cases with organ failure, unconsciousness and death (Hildebrandt et al., 2002).

As regard GCS there was statistically significant difference among uncomplicated, complicated and dead patients. There were $80.7 \%$ of dead cases and $26.7 \%$ of complicated cases had GCS less than or equal to 8 . This was similar to results observed by Basar et al., (2011) where they found that the mean GCS values were 4 for patients who had died and 13 for discharged patients and there was a statistical correlation between GCS values and mortality, and low GCS values indicate the potential for respiratory insufficiency development and bad prognosis in acutely organophosphrous (OP)-poisoned patients admitted within 24 hours after exposure. Also Budhathoki et al., (2009) stated that GCS $<8$ had been more associated with mortality in poisoned children. Moreover Russell and Shobhan, (2009) found that a GCS $\leq 8$ is a useful indicator for the requirement of endotracheal intubation in toxic coma.

As regard blood $\mathrm{pH}$, the present study revealed that there was significant difference between uncomplicated, complicated and dead cases. Similarly, Louriz et al., (2009). Singh et al., (2011) mentioned that presence of acidosis was related to poor outcome in aluminum phosphide poisoning. Also, Hong et al., (2000) mentioned that patients with metabolic acidosis were also related to higher paraquat fatality and Hampson and Hauff, (2008) stated that in carbon monoxide-poisoned patients the mortality was related to the severity of metabolic acidosis.

Statistically significant difference was among uncomplicated, complicated and dead patients in the present study as regard decontamination, where emesis or gastric lavage was used in half of uncomplicated cases and $19.2 \%$ of dead cases. Regarding activated charcoal, 
$35.9 \%$ of uncomplicated cases and $3.8 \%$ of dead cases received activated charcoal. Gastric decontamination including lavage and activated charcoal administration are known to decrease the absorption of some ingested poisons provided they are done within one-hour post ingestion (Chiu et al., 2011).

Statistically significant difference was among uncomplicated, complicated and dead patients as regard usage of dialysis in the current study. Dialysis may be indicated for life-threatening ingestions involving watersoluble substances of low molecular weight and sever cases of poisoning (Zimmerman, 2003).

There was statistically significant difference among non complicated, complicated and dead patients as regard emergency treatment, where endotracheal intubation and mechanical ventilation were needed in the majority of dead cases. $38.4 \%$ of dead cases, $13.3 \%$ of complicated cases needed dopamine therapy. These results are similar to Singh et al., (2011) reported that most of dead poisoned cases in ICU cases received inotropic support and needed mechanical ventilation.

In the current study, linear regression analysis identified that causative agent, heart rate, systolic blood pressure, respiratory rate, blood $\mathrm{pH}$, mechanical ventilation and dopamine therapy are significant predictors of outcome while mode of toxicity, skin discoloration, coma scale, emesis or lavage, activated charcoal, dialysis and endotracheal intubation failed to be a predictor. These results coincide with those of Lam et al., (2010) and Malangu and Ogunbanjo (2009) who mentioned that the causative agent vary from place to place, and over time, due to the availability and use of different chemicals and other poisoning agents and doubling the incidence of pesticide poisoning in developing countries during the past decades which accounts for a large number of fatal outcomes despite increased ICU facilities. Also, our results coincide with those of Hsin et al., (2008) who reported that abnormal vital signs were significant predictors of poisoningrelated fatalities. Similarly, Jayashree and Singhi, (2011) mentioned that hypotension at admission was the most significant predictor of death in children admitted to the ICU with acute poisoning. Hu et al., (2010) mentioned that factors such as hypotension and respiratory failure upon presentation can predict overall poisoning related fatality in emergency department poisoned patients. And, Hampson and Hauff, (2008) mentioned that arterial blood $\mathrm{pH}$ was significant predictors of death in carbon monoxide poisoning. Nejad et al., (2012) mentioned that there was negative relation between mechanical ventilation need and outcome in aluminum phosphide intoxication. Rocker et al., (2004) mentioned that the use of inotropic agents or vasopressors was associated with a higher risk of death in ICU than no use of inotropic agents or vasopressors. Risk stratification and detection of high risk patients are very important in provision of health care with the limited resources in the emergency department (Lee et al., 2008).

\section{Conclusion}

The causative agent, heart rate, systolic blood pressure, respiratory rate, blood $\mathrm{pH}$, mechanical ventilation and dopamine therapy were significant predictors of outcome of acutely intoxicated patients in intensive care unit. Their routine assessment as early as possible can be beneficial to assess the poisoning severity, improve the management course and decide the pathway of care.

\section{Acknowledgments}

The authors thank the director, the medical and nursing staff in PCC, Ain Shams University for their help and support.

\section{References}

Agran P., Gautam K., Lal A. et al. (2001): Rates of pediatric and adolescent injuries by year of age. Pediatrics, 108: 45.

Basar C., Ali D., Mesut Y et al. (2011): The prognostic value of the Glasgow coma scale, serum acetylcholinesterase and leukocyte levels in acute organophosphorus poisoning. Ann. Saudi Med; 31(2): 163-166.

Baumann M. and Strout T. (2007): Triage of geriatric patients in the emergency department: validity and survival with the Emergency Severity Index. Ann. Emerg. Med; 49(2):234-240.

Budhathoki S., Poudel P., Shah D.et al. (2009): Clinical profile and outcome of children presenting with poisoning or intoxication: a hospital based study. Nepal. Medical College Journal, 11(3): 170-175.

Chiu L., Lim B., Vasu A. et al., (2011): Poison exposure in the emergency department: a Singaporean experience. Hong Kong j.emerg.med; 18:197203.

Davies J., Eddleston M. and Buckley N. (2008): Predicting outcome in acute organophosphorus poisoning with a poison severity score or the Glasgow coma scale. Q J Med; 101:371-379.

Donna C., Douglas B. and David R. (2011): Epidemiology and outcomes of patients admitted to critical care after self poisoning. JICS; $12: 4$.

Goel A. and Aggarwal P., (2007): Pesticide poisoning .Natl Med J India; 20:182-91.

Hampson N. and Hauff N. (2008): Risk factors for shortterm mortality from carbon monoxide poisoning treated with hyperbaric oxygen. Crit Care Med; 36:2523-2527.

Hassanian H., Baghbanian N. And Kolahi A. (2007): Evaluating the factors accompanying coma in patients admitted to the poisoning ICU of Loghman-Hakim Poison Hospital. Iran J. Toxicol;1: 56-62.

Heffner J. and Barbieri C. (2000): End-of-life care preferences of patients enrolled in cardiovascular rehabilitation programs. Chest; 117: 1474-1481. 
Heyland D., Rocker G., Dodek P. et al (2002): Family satisfaction with care in the intensive care unit: Results of a multiple center study. Crit Care Med; 30:1413-1418.

Hildebrandt B., Wust P., Ahlers O. et al. (2002): The cellular and molecular basis of hyperthermia. Critical Reviews in Oncology/Hematology, 43(1):33-56.

Hong S., Yang D. and Hwang K. (2000): Associations between laboratory parameters and outcome of paraquat poisoning. Toxicology Letters, 53-59.

Hsin L., Hung L., Steve Y. et al. (2008): Presentations of patients of poisoning and predictors of poisoning related fatality: finding from a hospital based prospective study. BMC Public Health; 8:7-9.

Hu Y., Chou H., Lu W. et al. (2010): Features and prognostic factors for elderly with acute poisoning in the emergency department. J. Chin. Med. Assoc; 73(2):78-87.

Islambulchilar M., Islambulchilar Z. and Kargar-Maher M. (2009): Acute adult poisoning cases admitted to a university hospital in Tabriz, Iran. Hum Exp Toxicol; 28: 185-190.

Jayashree M.and Singhi S. (2011): Changing Trends and Predictors of Outcome in Patients with Acute Poisoning Admitted to the Intensive Care. J. Trop. Pediatr; 57(5):340-346.

Kao L. and Nanagas K. (2004): Carbon monoxide poisoning. Emerg Med Clin N Am; 22: 9851018.

Khadka S. and Ale S. (2005): A study of poisoning cases in emergency Kathmandu Medical College Teaching Hospital. Kathmandu University Med $\mathrm{J} ; 3: 388-391$.

Lam S., Lau A. and Yan W. (2010): Over 8 years experience on severe acute poisoning requiring intensive care in Hong Kong. China. Hum. Exp. Toxicol; 29: 757-765.

Lee, C.; Shih, C.; Hsu, K. et al. (2008): "The early prognostic factors of glyphosate-surfactant intoxication.”Am. J. Emerg. Med., 26:275-281.

Litovitz T.L., Klein W., White S. et al., (2001): 2000 annual report of American association of poison control centers toxic exposure surveillance system. AMJ Emerg Med; 19:337-95.

Louriz M., Dendane T., Abougal R. et al. (2009): Prognostic factors of acute aluminum phosphide poisoning in India. J Med Sci; 63:227-34.
Lund C., Vallersnes O., Dag J. et al. (2012): Outpatient treatment of acute poisonings in Oslo: poisoning pattern, factors associated with hospitalization, and mortality Scandinavian Journal of Trauma, Resuscitation and Emergency Medicine; 20(1):10.

Malangu N. and Ogunbanjo G. (2009): A profile of acute poisoning at selected hospitals in South Africa. South Afr J Epidemiol Infect; 24(2): 14-16.

Nejad F., Mohammadi A., Behnoush B.et al. (2012): Predictors of Poor Prognosis in aluminum phosphide intoxication. Iranian Journal of Toxicology, 6(16): 610-614.

Philip M. and Janice L. (2008): Toxicology in the Critical Care Unit. Chest, 133:1006-1013.

Rocker G., Deborah C., Sjokvist P. et al. (2004): Clinician predictions of intensive care unit mortality. Crit Care Med; 32:1149-1154.

Russell D. and Shobhan T. (2009): Decreased Glasgow Coma Scale Score Does Not Mandate Endotracheal Intubation in the Emergency Department. J. Emerg. Med.; 37(4):451-455.

Saddique A. (2001): Poisoning in Saudi Arabia: TenYear experience in King Khalid University Hospital. Annals of Saudi Medicine, 21:88-91.

Schwake L., Wollenschlager I., Stremmel W. et al. (2009): Adverse drug reactions and deliberate self-poisoning as cause of admission to the intensive care unit: a 1-year prospective observational cohort study. Intensive Care Med; 35:266-274.

Singh O., Javari Y., Juneja D. et al. (2011): Profile and outcome of patients with acute toxicity admitted in intensive care unit: Experiences from a major corporate hospital in urban India. Indian $\mathrm{J}$ Anaesth; 55:370-4.

Taghaddosinejad F., Sheikhazadi A., Yaghmaei A. et al. (2012): Epidemiology and Treatment of Severe Poisoning in the Intensive Care Unit: Lessons from a One-Year Prospective Observational Study. J Clinic Toxicol; http://dx.doi.org/10.4172/2161-0495.S1-007.

Yu J., Weng Y., Chen K. et al. (2012): Triage vital signs predict in-hospital mortality among emergency department patients with acute poisoning: a case control study BMC Health Services. Research, 12:262-268.

Zimmerman J. (2003): Poisonings and Overdoses. ACCP Critical Care Board Review; 365- 378. 


\section{الملخص العربيى}

التنبؤ بالنتيجة لمرضى التسمم الحاد بوحدة العناية المركّزة بمركز علاج التسمم بجامعة عين شمس

\section{اسماء احمد عساف و منال على عبد الكريم' و مروة احمد حسب النبى"}

مقدمة البحث: يشكل التسمم الحاد نسبة كبيرة من حالات وحدة العناية المركزة وعلى الرغم من أن معدل الوفيات عموما قد يكون منخفض

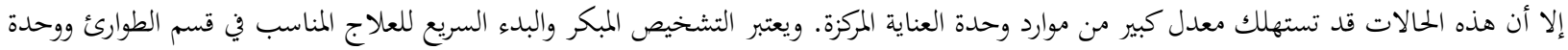
العناية المركزة هاما جدا لخفض معدلات الاعتلال والوفيات لمرضى التسمم في المستشفيات وكذلك التكلفة.

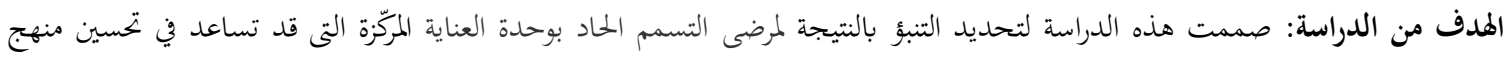
الإدارة و تنظيم العمل بالرعاية.

طريقة البحث: تم عمل هذة الدراسة بأثر رجعي لمرضى حالات التسمم التى تم ادخالها وحدة العناية المركزة في مركز علاج التسمم بمستشفيات

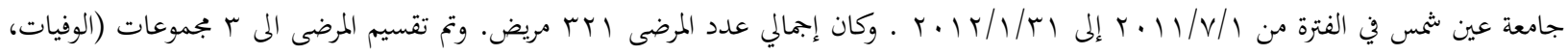

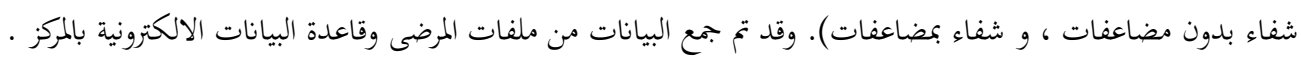

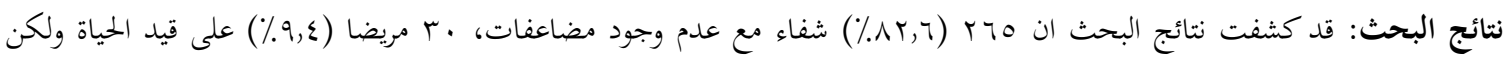

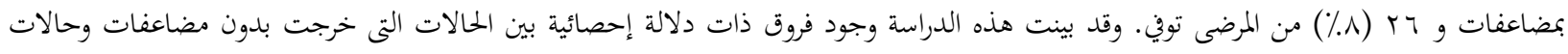
المضاعفات والوفيات من حيث أسلوب التّسمّم, العامل المسبب للتسمم, ، معدل ضربات القلب، ضغط الدم الانقباضي، معدل التنفس، تغيرات الجلد,

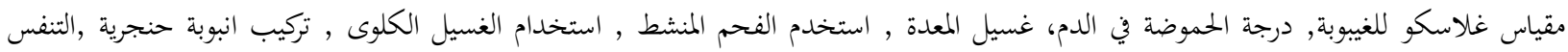
الصناعى والعلاج بالدوبامين.

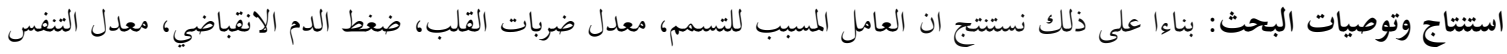

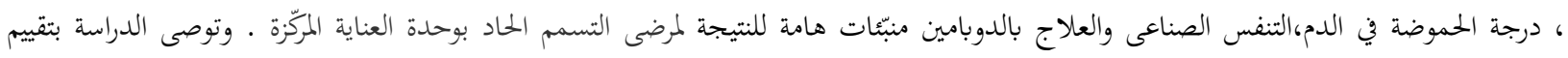

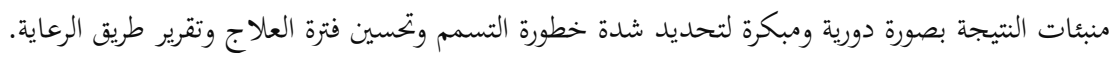

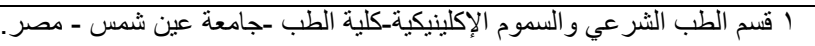

